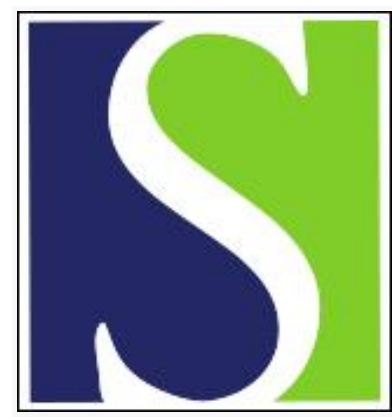

Scand J Work Environ Health 2014;40(6):597-609

https://doi.org/10.5271/sjweh.3437

Published online: 23 May 2014, Issue date: 01 Nov 2014

A longitudinal study on risk factors for neck and shoulder pain among young adults in the transition from technical school to working life

by Hanvold TN, Wærsted M, Mengshoel AM, Bjertness E, Twisk J, Veiersted KB

The results indicate that neck and shoulder pain increases during the transition from technical school to working life and that both work-related and individual factors are associated with pain development. This knowledge may help in improving early intervention strategies aiming to increase a sustainable work life among young adults.

Affiliation: National Institute of Occupational Health, P.O Box 8149 Dep., 0033 Oslo, Norway. tno@stami.no

Refers to the following texts of the Journal: 2001;27(1):41-48

2003;29(2):124-133 2005;31(5):375-386 2006;32(3):190-197

Key terms: electrician; hairdresser; longitudinal; longitudinal study; mechanical workload; musculoskeletal disorder; neck pain; pain; prospective study; shoulder pain; technical school; working life; young adult; young worker

This article in PubMed: www.ncbi.nlm.nih.gov/pubmed/24858779

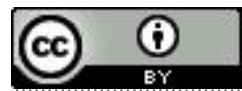




\title{
A longitudinal study on risk factors for neck and shoulder pain among young adults in the transition from technical school to working life
}

\author{
by Therese N Hanvold, MSc, ${ }^{1}$ Morten Wærsted, PhD, ${ }^{1}$ Anne Marit Mengshoel, PhD, ${ }^{2}$ Espen Bjertness, \\ PhD, ${ }^{2,3}$ Jos Twisk, PhD, ${ }^{4}$ Kaj Bo Veiersted, PhD ${ }^{1}$
}

\begin{abstract}
Hanvold TN, Wærsted M, Mengshoel AM, Bjertness E, Twisk J, Veiersted KB. A longitudinal study on risk factors for neck and shoulder pain among young adults in the transition from technical school to working life. Scand $J$ Work Environ Health. 2014;40(6):597-609. doi:10.5271/sjweh.3437
\end{abstract}

Objectives The study examined the course of neck and shoulder pain among a cohort of technical school students entering working life. We also aimed to identify work-related and individual risk factors for neck and shoulder pain during this transition period.

Methods The study was designed as a prospective cohort study following 420 technical school students (167 student hairdressers, 118 student electricians, and 135 media/design students) from school, through their apprenticeship and into working life. Every $4^{\text {th }}$ month over a 6.5 year period $(2002-2009)$, the participant's neck and shoulder pain for the preceding four weeks was assessed. Mechanical and psychosocial workplace factors as well as individual factors were evaluated at baseline and/or during the follow-up period. Data were analyzed by generalized estimating equations (GEE).

Results We found a significant increase in neck and shoulder pain over time in the transition from technical school to working life. High mechanical workload was associated with neck and shoulder pain among women, while a high level of shoulder muscle endurance capacity was associated with lower rates of neck and shoulder pain among men. Perceived muscle tension and ethnicity were the most consistent predictors for neck and shoulder pain, found among both women and men.

Conclusion Increased neck and shoulder pain was found in the transition from technical school to working life, and both work-related and individual factors were associated with pain development.

Key terms electrician; hairdresser; mechanical workload; musculoskeletal disorder; prospective; young worker.

As the second greatest cause of disability and having the fourth greatest impact on overall health, musculoskeletal disorders are a major problem globally (1). It is well known that musculoskeletal disorders are a common problem among the working population. In Norway, diagnoses related to musculoskeletal pain, injuries, and disorders are the cause of more than $40 \%$ of all sick-leave and $30 \%$ of all disability pensions (2). This coincides with a high and increasing prevalence of musculoskeletal pain among young adults (3). Pain in childhood/adolescence tends to persist $(4,5)$, and it has been hypothesized that the basis of pain in adulthood may be formed at an early age (6). Among Norwegian adolescents (aged 13-18), about half of the girls and one third of the boys reported chronic non-specific musculoskeletal pain (7). The neck and shoulder region was most commonly affected (7). In a study among newly employed workers, 24\% reported shoulder pain while $15 \%$ reported new onset of shoulder pain after one year (8). In a subsample of the current cohort, we found that young adults reporting neck and shoulder pain during technical school had a three times higher risk of reporting pain after entering working life (9). Considering the pain before entering working life may therefore be of importance when examining the

1 National Institute of Occupational Health, Oslo, Norway.

2 University of Oslo, Institute of Health and Society, Oslo, Norway.

3 Tibet University Medical College, Tibet, Lhasa, China.

4 VU University Medical Center, Amsterdam, The Netherlands.

Correspondence to: Therese Nordberg Hanvold, National Institute of Occupational Health, PO Box 8149 Dep., 0033 Oslo, Norway. [E-mail: tno@stami.no] 
persistence or deterioration of pain and identifying the effect of possible work-related risk factors.

Mechanical and psychosocial workplace factors have both been related to neck and shoulder pain (10-12). Individual factors such as physical capacity and gender may also be of importance $(13,14)$. Studies on middleaged and older workers have shown that both mechanical workload (15) and psychosocial factors at work (16, 17) may increase the risk of neck and shoulder pain. However few studies have been done evaluating these risk factors among young adults in their first years of working life. The objective of this study was to examine the course of neck and shoulder pain among a cohort of technical school students entering working life and identify work-related and individual risk factors for neck and shoulder pain in this period. The identification of risk factors for neck and shoulder pain early in working life is important as it could improve intervention strategies aimed at reducing pain development and increase the possibility for young workers to sustain their working careers.

\section{Methods}

\section{Study design and population}

The study was initiated in 2002 and recruited students from 13 different technical schools in the greater Oslo area in Norway. The study was designed as a prospective cohort study following the students from school, through their apprenticeship and into working life. The data collection was conducted from October 2002 to February 2009. The baseline assessment (T0) took place at school during school hours. Of the 496 invited, a total of 420 participated, giving a response rate of $85 \%$. Approximately every four months in the follow-up period, a questionnaire was mailed to the participants' home address, giving a total of 20 questionnaires during the 6.5 -year-follow-up period (T1-T20, table 1). At the time of the first three questionnaires (T0-T2, October 2002-June 2003), the participants were still attending school. During the collection of the following seven questionnaires (T3-T9, September 2003-May 2005), most of the participants were under apprenticeship. At the time of the last 11 questionnaires (T10-T20, October 2005-February 2009), most of them had entered working life. Table 1 gives more information on the study design and information on the amount of missing data during the follow-up period.

Of the 420 participants [ 153 men, 267 women, mean age 17.5 (standard deviation 1.2) years] recruited in their second year of technical school, $28 \%$ studied to become electricians, $40 \%$ studied hairdressing, and $32 \%$ studied media and design. All participants were followed-up the entire study period, regardless of their change in occupational status. At baseline three of the participants reported suffering from heart disease and one participant had rheumatoid arthritis, they were, however not excluded from the analysis. See table 2 for further background characteristics of the study group (table 2).

\section{Work-related factors}

Technical school background. The participant's technical school field affiliation (electrician, hairdresser or media/ design) at time of enrollment (T0), was noted and treated as a time-constant variable. However, changes in occupational status were monitored at every time point in the study period allowing us also to consider the changes in working status.

Mechanical workload. The participant's self-reported mechanical workload was assessed at baseline and in nine questionnaires duing the follow-up period (table 1). Twelve questions were used to assess the work-related mechanical exposure (18). The participants were asked whether their work involved or required repetitive movements (one question), precision movements (one question), manual material handling (two questions), vibration (one question) and body postures (seven questions) such as working with their arms elevated or their back twisted or bent forward. The three response alternatives were: 0 (nothing/hardly nothing), 1 (somewhat), and 2 (a great deal). On the basis of the 12 questions, an index was calculated ranging from 0-24 (18). Index quartiles have been used to categorize the exposure (18), we chose, however, to convert the index into three categories: low (0-6), medium (7-11), and high (12-24) on the basis of distribution of the data.

Psychosocial work factors. The participants psychosocial working conditions were monitored in five questionnaires during the follow-up period (see table 1) but were not assessed at baseline. Items were selected from the General Nordic Questionnaire for Psychological and Social Factors at Work $\left(\mathrm{QPS}_{\text {Nordic }}\right)$ (19). Quantitative demands and control over work intensity were each assessed by two questions. The questions on quantitative work demand were: "Is your workload irregular so that the work piles up?" and "Do you have too much to do?". The questions assessing control over work intensity were: "Can you set your own work pace?" and "Can you determine the length of your own breaks?". All the questions had 5 response alternatives ranging from 0 (never/ seldom) to 4 (often/very often). The mean of the two questions made the score for each of the psychosocial working conditions. The mean score was also converted into three categories: low (0-1), medium (1.1-2), and high (2.1-4), as done in an earlier study (20). 
Table 1. Study design (2002-2009), risk factors, outcome and number of participants ( $N=420)$.

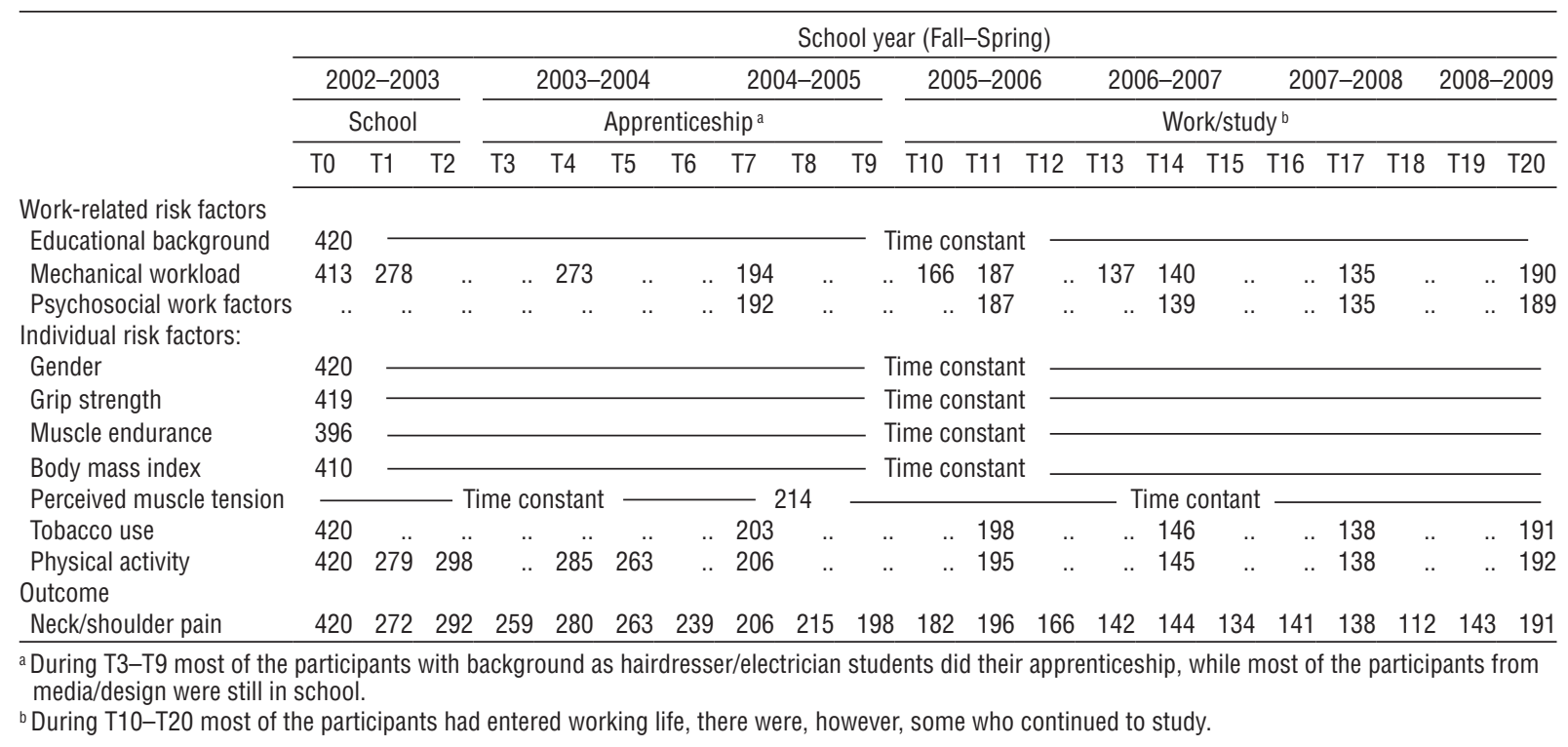

Table 2. Individual characteristics of the participants at baseline.

\begin{tabular}{|c|c|c|c|c|c|c|c|c|c|c|c|c|c|c|c|}
\hline \multirow[t]{2}{*}{ Variables } & \multicolumn{4}{|c|}{ All $(N=420)$} & \multicolumn{3}{|c|}{ Media/design $\quad(\mathrm{N}=135)$} & \multicolumn{4}{|c|}{ Electrician ( $\mathrm{N}=118$ ) } & \multicolumn{4}{|c|}{ Hairdresser (N=167) } \\
\hline & $\mathrm{N}$ & $\%$ & Median & Range & $\mathrm{N}$ & $\%$ & Median Range & $\mathrm{N}$ & $\%$ & Median & Range & $\mathrm{N}$ & $\%$ & Median & Range \\
\hline \multicolumn{16}{|l|}{ Gender } \\
\hline Men & 153 & 36 & & & 36 & 27 & & 113 & 96 & & & 4 & 2 & & \\
\hline Women & 267 & 64 & & & 99 & 73 & & 5 & 4 & & & 163 & 98 & & \\
\hline \multicolumn{16}{|l|}{ Ethnicity } \\
\hline Western & 348 & 83 & & & 107 & 79 & & 98 & 83 & & & 143 & 86 & & \\
\hline Non western & 72 & 17 & & & 28 & 21 & & 20 & 17 & & & 24 & 14 & & \\
\hline \multicolumn{16}{|l|}{ Socioeconomic background } \\
\hline Low & 66 & 16 & & & 17 & 13 & & 18 & 15 & & & 31 & 19 & & \\
\hline Moderate/high & 354 & 84 & & & 118 & 87 & & 100 & 85 & & & 136 & 81 & & \\
\hline \multicolumn{16}{|l|}{ Tobacco use } \\
\hline No & 201 & 48 & & & 72 & 53 & & 59 & 50 & & & 70 & 42 & & \\
\hline Yes & 219 & 52 & & & 63 & 47 & & 59 & 50 & & & 97 & 58 & & \\
\hline Mechanical workload (0-24) & & & 8 & $0-19$ & & & $6 \quad 0-15$ & & & 9 & $1-19$ & & & 9 & $2-17$ \\
\hline Body mass index & & & 21.7 & $16-40$ & & & $21.3 \quad 16-34$ & & & 22.6 & $16-37$ & & & 21.9 & $16-40$ \\
\hline Perceived muscle tension $(0-2$ & 2) a a & & 7 & $0-18$ & & & $6 \quad 0-17$ & & & 6 & $0-17$ & & & 8 & $0-18$ \\
\hline Hand grip strength $(\mathrm{kg})$ & & & 28.5 & $3.5-64$ & & & $27.5 \quad 13-62$ & & & 42.5 & $27-64^{b}$ & & & 25.5 & $3.5-55.5^{c}$ \\
\hline Shoulder muscle endurance se & econds ${ }^{f}$ & & 200 & $3-900$ & & & $19542-900$ & & & 300 & $72-900^{d}$ & & & 173 & $3-900$ \\
\hline Physical activity in leisuretime & $(0-6)$ & & 3 & $0-5$ & & & $0-6$ & & & 4 & $0-6$ & & & 3 & $0-6$ \\
\hline
\end{tabular}

Individual factors

Ethnicity. The participant's ethnicity was based on parental background and divided in "western" (both mother and father from western countries) and "non-western" (one or both parents from non-western countries).

Hand grip strength. Hand grip strength was tested at baseline and treated as time independent. The test was performed in standing position with the hands pointing downward. Each participant performed three maximal contractions with their dominant hand using a hand dynamometer, model 78010, (Lafayette Instrument, IN, USA). The highest of three attempts was recorded (21). The score was on the basis of data distribution also dichotomized into low and high categories, $0-29.5$ and $30-64 \mathrm{~kg}$, respectively. 
Shoulder muscle endurance capacity. The shoulder muscle endurance was tested at baseline and treated as time independent. The isometric endurance capacity in the shoulder muscles was quantified by the time (seconds) the participants could keep both shoulders abducted at $45^{\circ}$ with a load of $2 \mathrm{~kg}$ on each wrist. They were asked to hold the position as long as possible. This was done in concordance with protocol from a previous study (22). An upper limit was set at 900 seconds (15 minutes). Four participants reached this limit. On the basis of the data distribution, the score was further converted into three categories: low, medium, and high $(0-155$, 156-245, and 246-900 seconds, respectively).

Perceived muscle tension. The participants self-reported muscle tension was also considered as a time independent covariate and assessed in one questionnaire during the follow-up period (T8). The assumption that muscle tension was stable over time (time independent) was based on analyses of a subsample where the perceived muscle tension was assessed at three different time points and the score from the two following time points (T14 and T17) were significantly correlated with the score at $\mathrm{T} 8$ (Spearman`s $\rho=0.67, \mathrm{P}<0.01$ and $\rho=0.55, \mathrm{P}<0.01$ ). Perceived muscle tension was evaluated by 11 questions on muscle-tension habits. The questions concerned whether the subjects had the habit of raising their shoulders, contracting their neck muscles, holding tools unnecessarily tensely, contracting their stomach muscles, wrinkling the forehead, contracting the eyelids, contracting the chewing muscles, holding their breath tensely, sitting on the front part of the chair and grinding their teeth. Each question had three response alternatives ranging from 0 (never) to 2 (often) giving a muscle tension index ranging from $0-22$ (23). The score was also converted into three; low (0-4), medium (5-10) and high (11-22).

Physical activity level in leisure time. One question was used to measure the level of physical activity during leisure time at baseline and in nine questionnaires during the follow-up period (see table 1): "How often do you perform activities that lead to increased heart rate and shortness of breath?". There were seven response categories ranging from 0 (never) to 6 (everyday) (24). The score was in addition dichotomized into two categories: "once a week or less" (0-3) and "twice a week or more" (4-6) as done in an earlier study of a subsample of this cohort (25).

Tobacco use. The participants were also asked about their smoking and snuff habits. If they either were smokers or used snuff daily or occasionally they were characterized as tobacco users. This tobacco use was assessed at baseline and monitored in five questionnaires during the follow-up period (see table 1).
Neck and shoulder pain. The participant's neck and shoulder pain for the preceding four weeks was assessed at all 21 timepoints (T0-T20). The questionnaires included a mannequin drawing from the "Nordic Questionnaire on musculoskeletal symptoms" with shaded areas indicating the shoulder and neck region to give a united understanding of the pain region (26). The questionnaire assessed pain intensity [no (0), mild (1), moderate (2), and severe (3) pain] and pain duration [1-5 (1), 6-10 (2), 11-14 (3), and 15-28 (4) days] (27). A pain index was calculated by multiplying pain intensity (0-3) and duration (1-4), giving a pain index ranging from $0-12$. The reliability of this method has been found acceptable (28). For illustrative purposes, the neck and shoulder pain index (0-12) was also categorized into no pain ( 0$)$ and three different levels of pain severity: mild (1), moderate (2-3), and moderate/ severe (4-12) pain.

\section{Missing data and imputation procedures}

In our study, some of the time-varying variables were not assessed in all 20 questionnaires of the follow-up period and thus were missing by design (mechanical workload, psychosocial working conditions, tobacco use, and physical activity). There was also missing data when the participants did not answer one or more of the questionnaires (unit non-responders) or did not complete single items in a questionnaire (item non-responders). The response rate for the questionnaires ranged from $100 \%(\mathrm{~N}=420)$ at $\mathrm{T} 0$ to $27 \%(\mathrm{~N}=113)$ at $\mathrm{T} 18$. A total of 21 participants $(5 \%)$ answered all the 21 questionnaires and a total of 183 participants (44\%) answered $>50 \%$ of the questionnaires. Thirty participants (7\%) were missing in all follow-up questionnaires, only answering at baseline. See table 1 for more information on the missing data. Multiple imputations of all missing values were done based on a linear mixed model (29). The imputation model included all the variables that are used in the multivariate analysis in this study. Five imputed datasets were made, on the basis of which an average estimate was calculated (30).

\section{Statistical analysis}

Statistical analyses were done using STATA 12.0 (StataCorp, College Station, TX, USA). To examine the course of neck and shoulder pain in the study period, generalized estimating equations (GEE) analysis was used. This model takes into account the correlation between the repeated measurements within the individual. Due to over dispersion in the discrete outcome variable, a negative binomial GEE analysis was used. For the effect estimates, rate ratio (RR), with corresponding $95 \%$ con- 


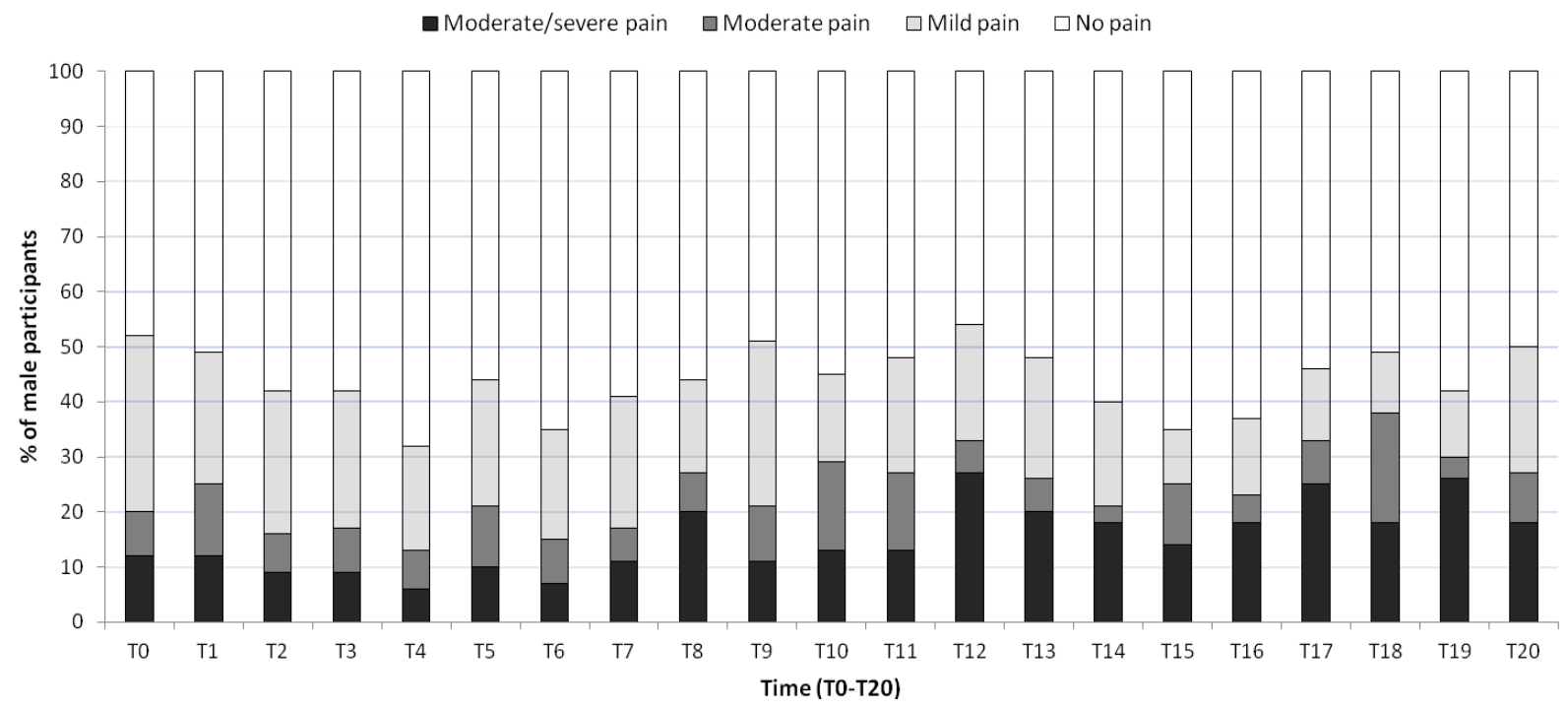

Figure 1a. Neck and shoulder pain prevalence among male technical school students (T0-T2) in apprenticeship (T3-T9) and entering working life (T10-T20). Neck and shoulder pain (0-12) are categorized in four levels: no (0), mild (1), moderate (2-3), and moderate/severe ( $\geq 4)$ pain. The prevalence $(\%)$ of each pain level is reported at each time point (TO-T20), $\mathrm{N}=153$.

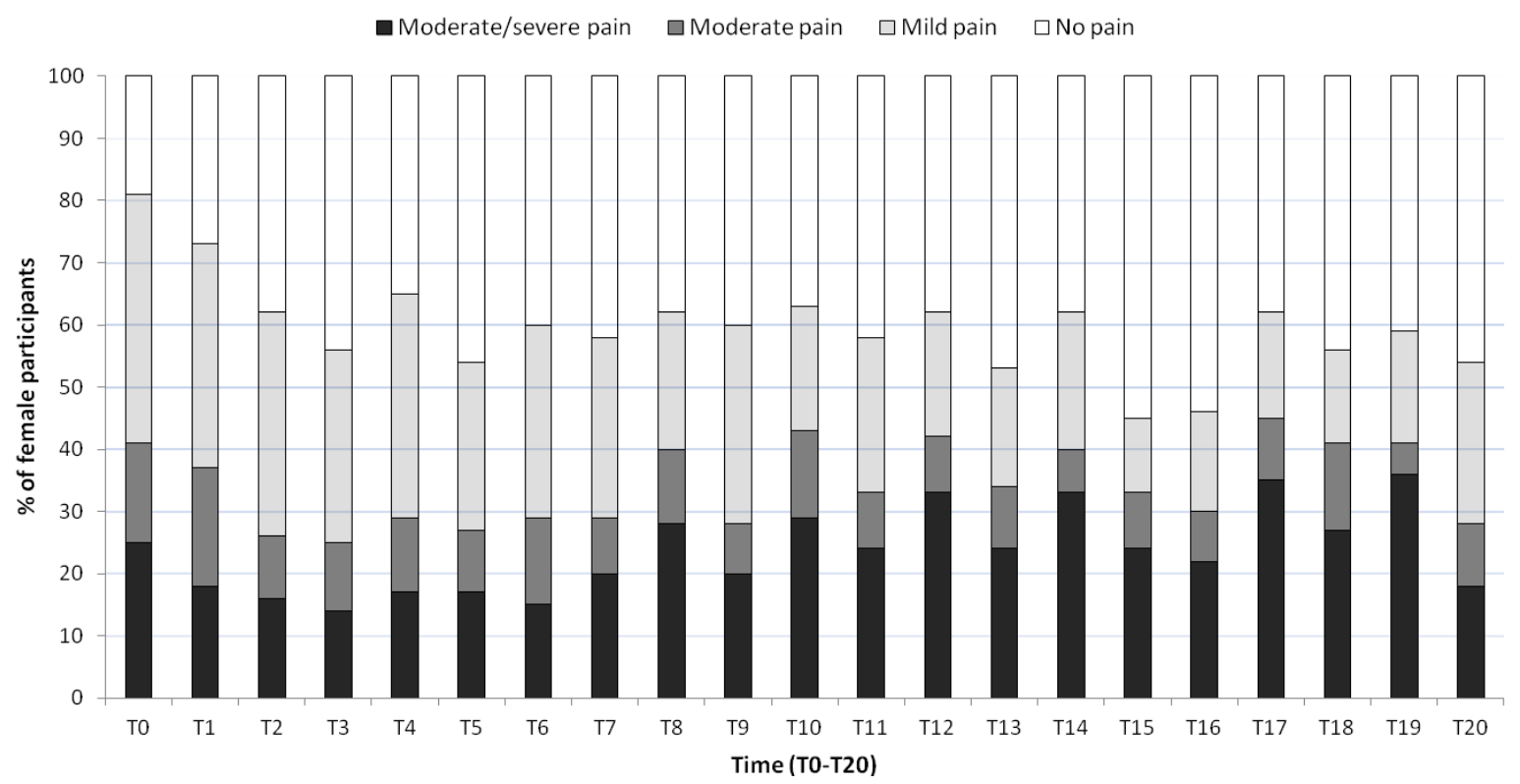

Figure. 1b. Neck and shoulder pain prevalence among female technical school students (T0-T2) in apprenticeship (T3-T9) and entering working life (T10-T20). Neck and shoulder pain (0-12) are categorized in four levels: no (0), mild (1), moderate (2-3), and moderate/severe ( $\geq 4)$ pain. The prevalence $(\%)$ of each pain level is reported at each time point (T0-T20), $\mathrm{N}=267$.

fidence intervals $(95 \% \mathrm{CI})$ were reported. In all negative binomial GEE analysis, an exchangeable correlations structure was used. The multivariate analyses were adjusted for covariates selected for inclusion a priori. Only variables significant at $\mathrm{P}<0.05$ in the univariate analyses were reported in the multivariate analyses. Because of the gender difference in effect of pain over time the univariate and multivariate analyses were also stratified by gender.

\section{Ethics}

The Norwegian Data Inspectorate and the scientific ethical committee system approved the project. All partici- 
pants gave their written consent and parental consent was obtained for those younger than 18 years at baseline.

\section{Results}

A high prevalence of neck and shoulder pain was seen at baseline (T0), with $71 \%$ of the participants reporting pain of any level the preceding four weeks. Differentiating three levels of neck and shoulder pain showed that $37 \%$ reported mild, $13 \%$ moderate, and $21 \%$ moderate/ severe pain at baseline. Women reported a higher prevalence of pain compared to men during the whole period. Figures $1 \mathrm{a}$ and $1 \mathrm{~b}$ illustrate the course of neck and shoulder pain prevalence for men and women separately. Both genders showed a decreasing trend in the prevalence of any pain, while the prevalence of moderate/severe pain showed an increasing trend over time.

Analyses of the course of neck and shoulder pain as a discrete variable (index 0-12) also showed a significant gender difference in pain reports. Women had a 1.5-times-higher rate of neck and shoulder pain compared to male participants during the study period $(\mathrm{RR}=1.50,95 \%$ CI $1.24-1.81, \mathrm{P}<0.01)$. A significant increase in pain over time was seen for the whole group $(\mathrm{RR}=1.02,95 \% \mathrm{CI} 1.01-1.03, \mathrm{P}<0.01)$ and for both genders in the stratified analyses. Stratifying the analyses by technical school background also showed a significant increase of neck and shoulder pain over time among media/design students $(\mathrm{RR}=1.01,95 \%$ CI $1.00-1.02$, $\mathrm{P}<0.01)$ and electrician/hairdresser students $(\mathrm{RR}=1.02$, $95 \%$ CI $1.01-1.03, \mathrm{P}<0.01)$. When further stratifying by gender, all groups showed a significant increase of neck and shoulder pain over time except female media/ design students ( $\mathrm{RR}=1.00,95 \% \mathrm{CI} 0.99-1.02, \mathrm{P}=0.67)$ (See figure 2). Among females, the participants with a background as hairdresser/electrician students showed a significant 1.3-times-higher rate of neck and shoulder pain compared to the female media/design students $(\mathrm{RR}=1.30,95 \%$ CI $1.06-1.55, \mathrm{P}<0.01)$. This was not seen when comparing the male electrician/hairdresser to media/design students $(\mathrm{RR}=0.87,95 \% \mathrm{CI} 0.60-1.25$, $\mathrm{P}=0.46$ ).

\section{Unadjusted analyses}

The unadjusted analyses (table 3 ) showed that higher perceived muscle tension, tobacco use and ethnicity were significantly associated with increased neck and shoulder pain. Higher level of shoulder-muscle endurance and hand-grip strength was significantly associated with lower rates of neck and shoulder pain. Stratifying analyses by gender showed that mechanical workload was positively associated with increased neck and shoul- der pain among women but not men. A high level of muscle endurance was, on the other hand, significantly associated with lower rates of neck and shoulder pain among men but not women. In both genders, there was a significant association between perceived muscle tension and neck and shoulder pain.

\section{Adjusted analyses}

In the adjusted analyses (table 4) perceived muscle tension and ethnicity were the two variables that remained statistically significant for the whole group. Participants who reported a high level of perceived muscle tension had a $56 \%$ higher rate of neck and shoulder pain compared to those reporting low levels of muscle-tension habits. This association was the most persistent of the risk factors in our study, remained statistically significant after adjustments and stratification by gender, and showed a clear gradient from low to high levels in all analyses. Individuals with parents from non-western countries reported almost 30\% more neck and shoulder pain compared to participants with parents from western countries. This association was found both among men and women, but among male participants the association was borderline statistically significant. The adjusted analyses stratified by gender showed a significant association between mechanical workload and neck and shoulder pain only among female participants. Each additional increase in the mechanical workload $(0-24)$ was associated with an estimated $1 \%$ increase in neck and shoulder pain among women. An association between shoulder muscle endurance and neck and shoulder pain was only found for male participants. Excluding the adjustment of educational background in the multivariate analyses did not change the results, however, a slightly increased significant level for mechanical workload among women was seen $(\mathrm{RR}=1.01,95 \% \mathrm{CI}$ $1.00-1.02, \mathrm{P}=0.03$ ). Excluding the four male participants with a background as hairdressing students and the five female participants with a background as electrician students did not change the conclusions of the multivariate analyzes (results not shown).

Changes in the time-dependent work-related factors were analyzed and there was no statistically significant change in the self-reported mechanical workload over time for the whole group $(\mathrm{RR}=0.99,95 \%$ CI $0.99-1.00$, $\mathrm{P}=0.54$ ) or stratified by gender (women $\mathrm{RR}=0.99,95 \%$ CI 0.99-1.00, $\mathrm{P}=0.16$; men $\mathrm{RR}=1.00,95 \%$ CI $0.99-1.00$, $\mathrm{P}=0.54$ ). However, analyses showed a significant gender difference in mechanical workload over the study period, where women reported some $22 \%$ less mechanical workload compared to men ( $\mathrm{RR}=0.78,95 \%$ CI $0.73-0.82$, $\mathrm{P}<0.01$ ). Analyses also show that hairdresser/electrician students report a $36 \%$ higher workload compared to media/design students ( $\mathrm{RR}=1.36,95 \%$ CI 1.26-1.46, 


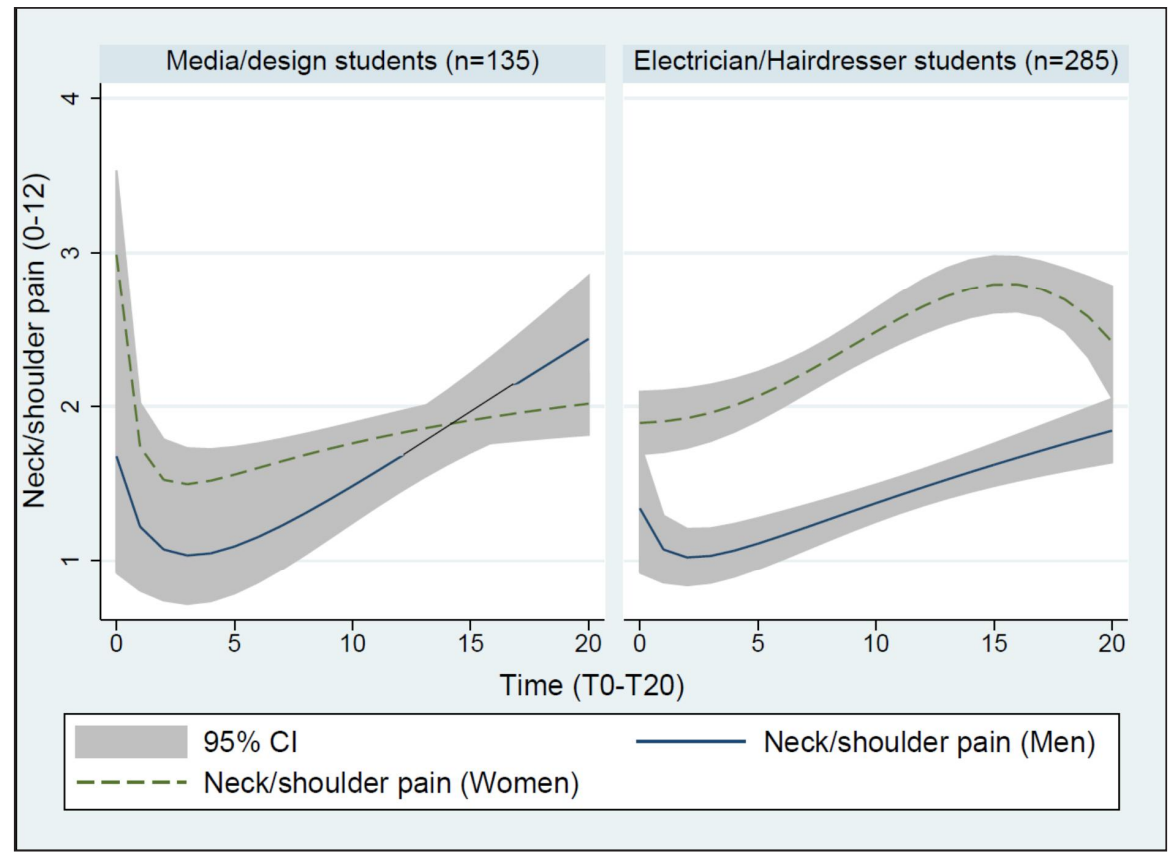

Figure 2. Fitted neck and shoulder pain (0-12) over time (T0-T20) with $95 \%$ confidence interval $(95 \%$ $\mathrm{Cl})$, divided by technical school background and gender $(\mathrm{N}=420)$.
$\mathrm{P}<0.01$ ). Figure 3 illustrates the changes in mechanical workload divided by gender and technical school background. Among women, the participants with a background in hairdressing showed a minor but significant decrease of mechanical workload over time $(\mathrm{RR}=0.99$, 95\% CI 0.99-0.99, $\mathrm{P}<0.01$ ), while female media/design students showed a slight increase $(\mathrm{RR}=1.01,95 \% \mathrm{CI}$ 0.99-1.01, $\mathrm{P}=0.05$ ). Among male participants with a background as electrician students, no significant change was seen in mechanical workload over time $(\mathrm{RR}=0.99$, $95 \%$ CI $0.99-1.00, \mathrm{P}=0.33$ ), while among the male media/design students, a significant increase was found $(\mathrm{RR}=1.02,95 \%$ CI $1.01-1.03, \mathrm{P}<0.01)$.

The psychosocial work factors showed a small but statistically significant increase for both quantitative working demands ( $R R=1.01,95 \%$ CI $1.00-1.01$, $\mathrm{P}<0.01)$ and control over work intensity $(\mathrm{RR}=1.01$, $95 \%$ CI $1.00-1.01, \mathrm{P}<0.01$ ) over the study period in the cohort. A significant increase was also found for both of the psychosocial working factors when stratifying by gender (results not shown).

Thirty-five percent of student hairdressers $(\mathrm{N}=59)$ and $19 \%$ of the student electricians $(\mathrm{N}=23)$ reported having changed their occupational status during the study period. The changes occurred throughout the follow-up with the most changes in the transition from apprenticeship to working life. The participants with a background as media/design students could end up in a variety of jobs or fields of study and most changes occurred in their third follow-up year (T7-T9). Of those reporting status at the last assessment (T20), 62\% with a back- ground in electrician studies were still working as electricians (12\% in other occupations and 26\% students/ unemployed). Of those with background in hairdressing studies, $30 \%$ were still in the same occupation ( $43 \%$ in other jobs and $26 \%$ studying/on maternity leave/unemployed). Of the male participants with a media/design background, $53 \%$ were still studying or unemployed and $47 \%$ held other occupations as bartenders/waiters or computer consultants). Among the female media/design participants, $58 \%$ were studying, on maternity leave, or unemployed while $42 \%$ were in different occupations such as retail or education.

\section{Discussion}

This study examined the course of neck and shoulder pain among young adults entering working life and found a significant effect of time and an increasing tendency towards moderate/severe pain levels. A weak but positive association with mechanical workload was found among women, while shoulder-muscle endurance was negatively associated with neck and shoulder pain among men. Perceived muscle tension and ethnicity were the most consistent risk factors for neck and shoulder pain for both women and men.

The neck and shoulder pain prevalence estimates in our study were similar to estimates of $52 \%$ found among workers aged 15-66 years in Norway (31). The moderate/severe pain prevalence in our study was also similar 
Table 3. The unadjusted generalized estimating equations (GEE) analyses of the association between neck and shoulder pain and workrelated and individual risk factors. [RR=rate ratio, $95 \% \mathrm{Cl}=95 \%$ confidence interval]

\begin{tabular}{|c|c|c|c|c|c|c|c|c|c|}
\hline \multirow[t]{3}{*}{ Risk factors } & \multicolumn{3}{|c|}{ All $(\mathrm{N}=420)$} & \multicolumn{3}{|c|}{ Men $(\mathrm{N}=153)$} & \multicolumn{3}{|c|}{ Women (N=267) } \\
\hline & \multicolumn{3}{|c|}{$\begin{array}{c}\text { Observations } \\
\mathrm{N}=8820 \text { (T0-20, 61/2 years) }\end{array}$} & \multicolumn{3}{|c|}{$\begin{array}{c}\text { Observations } \\
\mathrm{N}=3213 \text { (T0-20, 61/2 years) }\end{array}$} & \multicolumn{3}{|c|}{$\begin{array}{c}\text { Observations } \\
\mathrm{N}=5607 \text { (T0-20, } 61 / 2 \text { years) }\end{array}$} \\
\hline & $\mathrm{RR}$ & $95 \% \mathrm{Cl}$ & P-value & $\mathrm{RR}$ & $95 \% \mathrm{Cl}$ & P-value & $\mathrm{RR}$ & $95 \% \mathrm{Cl}$ & P-value \\
\hline \multicolumn{10}{|l|}{ Gender } \\
\hline Men & 1.00 & Reference & & & & & & & \\
\hline Women & 1.50 & $1.24-1.81$ & $<0.01$ & & & & & & \\
\hline \multicolumn{10}{|l|}{ Education } \\
\hline Media/design & 1.00 & Reference & & 1.00 & Reference & & 1.00 & Reference & \\
\hline Hairdresser/Electrician & 1.12 & $0.94-1.34$ & 0.22 & 0.87 & $0.60-1.26$ & 0.46 & 1.30 & $1.07-1.59$ & $<0.01$ \\
\hline Mechanical workload (0-24) & 1.00 & $0.99-1.01$ & 0.17 & 1.00 & $0.98-1.02$ & 0.91 & 1.01 & $1.00-1.02$ & 0.03 \\
\hline Low & 1.00 & Reference & & 1.00 & Reference & & 1.00 & Reference & \\
\hline Moderate & 1.01 & $0.92-1.10$ & 0.86 & 0.99 & $0.82-1.19$ & 0.90 & 1.02 & $0.92-1.13$ & 0.70 \\
\hline High & 1.05 & $0.95-1.16$ & 0.31 & 0.98 & $0.81-1.19$ & 0.84 & 1.11 & $0.98-1.25$ & 0.08 \\
\hline Control over work intensity (0-4) & 1.00 & $0.96-1.05$ & 0.99 & 1.03 & $0.97-1.11$ & 0.34 & 0.99 & $0.93-1.05$ & 0.71 \\
\hline Low & 1.00 & Reference & & 1.00 & Reference & & 1.00 & Reference & \\
\hline Moderate & 0.99 & $0.90-1.09$ & 0.86 & 0.99 & $0.85-1.16$ & 0.96 & 0.99 & $0.88-1.11$ & 0.87 \\
\hline High & 1.02 & $0.92-1.13$ & 0.74 & 1.11 & $0.94-1.31$ & 0.22 & 0.99 & $0.86-1.12$ & 0.83 \\
\hline Quantitative work demands (0-4) & 1.01 & $0.97-1.05$ & 0.56 & 1.02 & $0.94-1.10$ & 0.63 & 1.01 & $0.96-1.06$ & 0.64 \\
\hline Low & 1.00 & Reference & & 1.00 & Reference & & 1.00 & Reference & \\
\hline Moderate & 1.03 & $0.92-1.15$ & 0.64 & 1.02 & $0.80-1.30$ & 0.88 & 1.03 & $0.91-1.18$ & 0.61 \\
\hline High & 1.02 & $0.92-1.14$ & 0.68 & 0.98 & $0.78-1.23$ & 0.86 & 1.05 & $0.92-1.20$ & 0.45 \\
\hline Perceived muscle tension (0-22) & 1.05 & $1.03-1.07$ & $<0.01$ & 1.04 & $1.01-1.07$ & 0.02 & 1.04 & $1.02-1.06$ & $<0.01$ \\
\hline Low & 1.00 & Reference & & 1.00 & Reference & & 1.00 & Reference & \\
\hline Moderate & 1.18 & $0.96-1.45$ & 0.12 & 1.33 & $0.92-1.91$ & 0.13 & 1.03 & $0.81-1.32$ & 0.79 \\
\hline High & $1.71^{\mathrm{a}}$ & $1.38-2.12$ & $<0.01$ & 1.48 & $0.97-2.25$ & 0.06 & 1.59 & $1.25-2.03$ & $<0.01$ \\
\hline Handgrip strength (kg) & 0.98 & $0.98-0.99$ & $<0.01$ & 1.01 & $0.98-1.03$ & 0.57 & 0.99 & $0.97-1.01$ & 0.26 \\
\hline Low & 1.00 & Reference & & 1.00 & Reference & & 1.00 & Reference & \\
\hline High & $0.76^{a}$ & $0.65-0.91$ & $<0.01$ & 0.89 & $0.37-2.12$ & 0.79 & 1.04 & $0.84-1.31$ & 0.70 \\
\hline Muscle endurance (seconds) & 0.99 & $0.99-1.00$ & 0.07 & 0.99 & $0.99-1.00$ & 0.94 & 0.99 & $0.99-1.00$ & 0.30 \\
\hline Low & 1.00 & Reference & & 1.00 & Reference & & 1.00 & Reference & \\
\hline Moderate & 0.94 & $0.76-1.17$ & 0.59 & 0.59 & $0.36-0.96$ & 0.03 & 1.08 & $0.86-1.37$ & 0.50 \\
\hline High & 0.71 & $0.59-0.87$ & $<0.01$ & 0.57 & $0.37-0.86$ & $<0.01$ & 0.87 & $0.69-1.11$ & 0.26 \\
\hline Physical activity (0-6) & 0.98 & $0.96-1.00$ & 0.23 & 0.97 & $0.93-1.02$ & 0.20 & 0.99 & $0.97-1.02$ & 0.61 \\
\hline$\leq 1$ times per week & 1.00 & Reference & & 1.00 & Reference & & 1.00 & Reference & \\
\hline$\geq 2$ times per week & 0.97 & $0.90-1.04$ & 0.35 & 0.96 & $0.84-1.09$ & 0.51 & 0.98 & $0.90-1.06$ & 0.59 \\
\hline \multicolumn{10}{|l|}{ Tobacco use } \\
\hline No & 1.00 & Reference & & 1.00 & Reference & & 1.00 & Reference & \\
\hline Yes & 1.21 & $1.02-1.44$ & 0.03 & 1.32 & $0.96-1.83$ & 0.09 & 1.14 & $0.94-1.38$ & 0.19 \\
\hline \multicolumn{10}{|l|}{ Ethnicity } \\
\hline Western & 1.00 & Reference & & 1.00 & Reference & & & Reference & \\
\hline Non-western & 1.23 & $1.02-1.48$ & 0.03 & 1.31 & $0.90-1.91$ & 0.16 & 1.22 & $0.99-1.49$ & 0.06 \\
\hline Time (T0-T20) & 1.02 & $1.01-1.03$ & $<0.01$ & 1.03 & $1.02-1.04$ & $<0.01$ & 1.01 & $1.01-1.02$ & $<0.01$ \\
\hline
\end{tabular}

a The RR for all is not between the RR in the two subgroups. This can be explained by confounding by gender.

to the $19 \%$ reporting to be intensely bothered by pain during the preceding four weeks in a cohort of mainly non-manual workers (12). Weekly neck and shoulder pain among high school students have shown prevalence rates between $17-28 \%(32,33)$.

The course of any level of neck and shoulder pain in transition from school to working life showed a decreasing trend. A decrease in neck and shoulder pain after the baseline assessment has also been found in a previous observational study (27). This may illustrate a bias in the initial pain report related to the first assessment bringing attention to symptoms that the participants usually do not think about. The results show on the other hand an increase in the prevalence of moderate/severe pain reports in the study period, which may illustrate an effect of the transition into working life. However, it may also be an effect of time, consistent with the knowledge of increased pain with increasing age (34).

Females reported more neck and shoulder pain than males. This is a phenomenon found both in childhood (7) and adult working populations (35). There are several hypotheses explaining these gender differences [ie, the exposure $(36,37)$ and vulnerability $(38)$ hypotheses]. Adjusting for work-related and other individual factors, the gender difference became weaker although women still had a $33 \%$ higher rate of neck and shoulder pain compared to male participants. Comparing the results for women and men is difficult as the gender differences can hardly be disentangled from occupational differences. The gender dichotomy we have found may 
Table 4. The adjusted generalized estimating equations (GEE) analyses a of the association between neck and shoulder pain and workrelated and individual risk factors. [RR=rate ratio, 95\% $\mathrm{Cl}=95 \%$ confidence interval]

\begin{tabular}{|c|c|c|c|c|c|c|c|c|c|}
\hline \multirow[t]{3}{*}{ Risk factors } & \multicolumn{3}{|c|}{ All $(\mathrm{N}=420)$} & \multicolumn{3}{|c|}{ Men $(\mathrm{N}=153)$} & \multicolumn{3}{|c|}{ Women $(\mathrm{N}=267)$} \\
\hline & \multicolumn{3}{|c|}{$\begin{array}{c}\text { Observations } \\
\mathrm{N}=8820 \text { ( } \mathrm{T} 0-20,61 \frac{1}{2} \text { years) }\end{array}$} & \multicolumn{3}{|c|}{$\begin{array}{c}\text { Observations } \\
\mathrm{N}=3213 \text { (T0-20, } 61 / 2 \text { years) }\end{array}$} & \multicolumn{3}{|c|}{$\begin{array}{c}\text { Observations } \\
\mathrm{N}=5607 \text { (T0-20, 61/2 years) }\end{array}$} \\
\hline & $\mathrm{RR}$ & $95 \% \mathrm{Cl}$ & P-value & $\mathrm{RR}$ & $95 \% \mathrm{Cl}$ & P-value & $\mathrm{RR}$ & $95 \% \mathrm{Cl}$ & P-value \\
\hline \multicolumn{10}{|l|}{ Gender } \\
\hline Men & 1.00 & Reference & & & & & & & \\
\hline Women & 1.33 & $0.99-1.78$ & 0.05 & & & & & & \\
\hline \multicolumn{10}{|l|}{ Education } \\
\hline Media/design & 1.00 & Reference & & 1.00 & Reference & & 1.00 & Reference & \\
\hline Hairdresser/Electrician & 1.07 & $0.89-1.30$ & 0.47 & 0.77 & $0.53-1.11$ & 0.16 & 1.19 & $0.96-1.47$ & 0.12 \\
\hline Mechanical workload $(0-24)^{b}$ & 1.01 & $0.99-1.02$ & 0.08 & 1.00 & $0.99-1.02$ & 0.61 & 1.01 & $1.00-1.02$ & $<0.05$ \\
\hline Low & 1.00 & Reference & & 1.00 & Reference & & 1.00 & Reference & \\
\hline Moderate & 1.04 & $0.95-1.14$ & 0.38 & 1.07 & $0.90-1.27$ & 0.92 & 1.05 & $0.94-1.16$ & 0.39 \\
\hline High & 1.08 & $0.97-1.19$ & 0.16 & 1.03 & $0.86-1.24$ & 0.71 & 1.11 & $0.99-1.26$ & 0.08 \\
\hline Perceived muscle tension $(0-22)^{b}$ & 1.04 & $1.02-1.06$ & $<0.01$ & 1.04 & $1.01-1.08$ & 0.02 & 1.04 & $1.02-1.06$ & $<0.01$ \\
\hline Low & 1.00 & Reference & & 1.00 & Reference & & 1.00 & Reference & \\
\hline Moderate & 1.18 & $0.94-1.47$ & 0.15 & 1.42 & $0.99-2.05$ & 0.06 & 1.07 & $0.82-1.39$ & 0.64 \\
\hline High & 1.56 & $1.24-1.97$ & $<0.01$ & 1.53 & $0.96-2.43$ & 0.07 & 1.51 & $1.16-1.98$ & $<0.01$ \\
\hline Handgrip strength $(\mathrm{kg})^{\mathrm{b}}$ & 1.00 & $0.99-1.02$ & 0.98 & 1.01 & $0.99-1.03$ & 0.21 & 0.99 & $0.97-1.01$ & 0.50 \\
\hline Low & 1.00 & Reference & & 1.00 & Reference & & 1.00 & Reference & \\
\hline High & 1.04 & $0.81-1.35$ & 0.72 & 0.91 & $0.33-2.52$ & 0.86 & 1.07 & $0.83-1.37$ & 0.61 \\
\hline Muscle endurance (seconds) b & 1.00 & $0.99-1.00$ & 0.88 & 1.00 & $0.99-1.00$ & 0.99 & 0.99 & $0.99-1.00$ & 0.73 \\
\hline Low & 1.00 & Reference & & 1.00 & Reference & & 1.00 & Reference & \\
\hline Moderate & 0.96 & $0.77-1.21$ & 0.75 & 0.67 & $0.43-1.07$ & 0.10 & 1.06 & $0.83-1.35$ & 0.66 \\
\hline High & 0.85 & $0.68-1.06$ & 0.16 & 0.66 & $0.44-0.99$ & $<0.05$ & 0.94 & $0.75-1.19$ & 0.64 \\
\hline \multicolumn{10}{|l|}{ Tobacco us } \\
\hline No & 1.00 & Reference & & 1.00 & Reference & & 1.00 & Reference & \\
\hline Yes & 1.13 & $094-1.35$ & 0.20 & 1.32 & $0.95-1.85$ & 0.10 & 1.04 & $0.85-1.28$ & 0.68 \\
\hline \multicolumn{10}{|l|}{ Ethnicity } \\
\hline Western & 1.00 & Reference & & 1.00 & Reference & & & Reference & \\
\hline Non-western & 1.29 & $1.07-1.50$ & $<0.01$ & 1.42 & $0.98-2.08$ & 0.07 & 1.24 & $1.00-1.53$ & $<0.05$ \\
\hline Time (T0-T20) & 1.02 & $1.01-1.03$ & $<0.01$ & 1.03 & $1.02-1.05$ & $<0.01$ & 1.01 & $1.00-1.02$ & $<0.01$ \\
\hline
\end{tabular}

${ }^{a}$ The analyses are adjusted for the other variables listed in the table in addition to: control over work intensity, quantitative work demands and physical activity in leisure time. In addition adjustments for gender were done in the analyses of all subjects.

${ }^{\mathrm{b}}$ The continuous/discrete and categorized variables were analyzed separately.

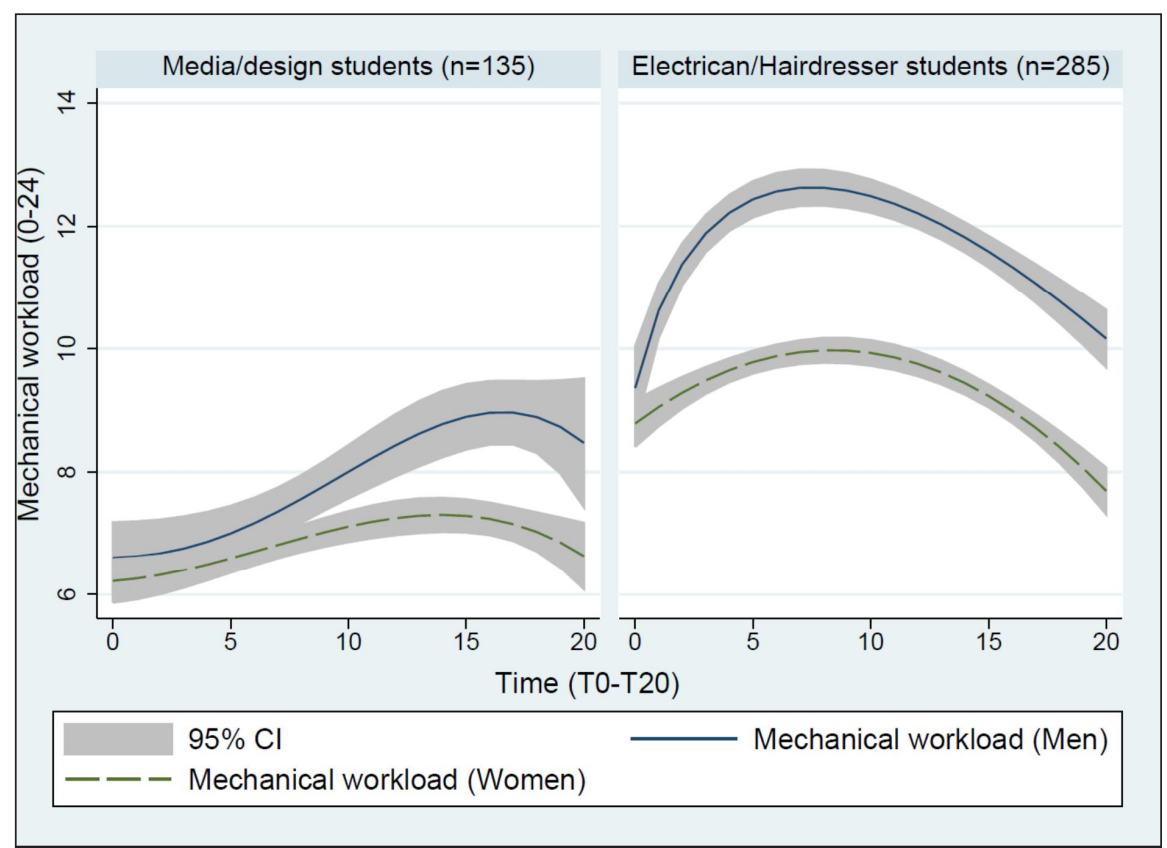

Figure 3. Fitted mechanical workload (0-24) over time (T0-T20) with 95\% confidence interval $(95 \% \mathrm{Cl})$, divided by technical school background and gender $(\mathrm{N}=420)$. 
be explained by the difference in their occupations as most of the electricians were male and most hairdressers were female. To address this, we conducted unadjusted analyses of associations separately for "pain and gender" and "pain and educational background". Females with a background as student hairdressers had more neck and shoulder pain in their first years of working life compared to females with a background in media/ design. These results are supported by a cross-sectional study comparing hairdressers with non-hairdressing controls (39). Males with a background in electrician studies showed less neck and shoulder pain compared to males with a background in media/design. This was unexpected as earlier studies have shown that workrelated musculoskeletal pain is over-represented among construction workers and older electricians $(40,41)$. This can indicate that using the "intention-to-treat" principle, disregarding changes in occupation during followup was inaccurate. However, analyzes done excluding those leaving their occupation as electricians during the follow-up did not change these results.

Among the general working population, both workrelated mechanical and psychosocial factors have been found as independent risk factors in the development of neck and shoulder pain $(20,42)$. These studies were all carried out among workers with a relatively long exposure time in working life compared to the young workers in our cohort. In a study of newly employed workers, however, evidence has been found to support the importance of mechanical work-related factors on the onset of new shoulder pain (8). Our results indicate that increased mechanical workload may play a role in the start of working life for the development of neck and shoulder pain, especially among women. No significant association between psychosocial work factors and neck and shoulder pain among young workers was found in our study, which is in contrast to other studies $(12,20)$. Our results are, however, supported by a study among newly employed workers (8). Perhaps simply being newly employed or in the first years of working life there is lower expectation of having control over work intensity compared with older more experienced workers. A significant increase over time for both work-related psychosocial factors was seen in our study, and - as suggested by Karasek in the demand-control model - high job control may buffer the effect of high job demands on workers health outcome (43).

Perceived muscle tension was consistently associated with neck and shoulder pain in our cohort. The literature supports this association $(11,44)$, and a prospective study among office workers assessing neck and shoulder pain every three months over one year showed that perceived muscle tension predicted future symptoms (45). An association between perceived muscle tension and vocational trapezius muscle activity measured by electromyography during pauses was found in an analyzes of a subsample from the current cohort (25). A study among females in service occupations found that their reported general tension was associated with the presence of psychosocial stress (46). In a longitudinal study of young adults (aged 15-18 years) psychosomatic stress symptoms increased the risk of developing neck and shoulder pain seven years later (32). The association between psychosomatic symptoms among adolescents and musculoskeletal pain in adulthood may be explained by increased tension (32).

Ethnicity was consistently associated with neck and shoulder pain and its importance has also been demonstrated in other studies on working populations (47, 48). It has been hypothesized that ethnicity may play an important role due to both biological and cultural differences in pain (49).

Shoulder muscle endurance was associated with lower levels of neck and shoulder pain among men in our cohort, coinciding with earlier studies of young adults $(50,51)$. An imbalance between exposure to mechanical workload and the individual's physical capacity might be a risk factor of musculoskeletal disorders. However, few quality studies have evaluated these associations, and a previous review has found the literature inconclusive (52).

\section{Methodological considerations}

One of the methodological strengths of our study is the longitudinal design with frequent and repetitive measurement of both the outcome and exposure variables. Studies with long follow-up often interpret associations between exposure at baseline and outcome at followup without considering changes in the period between the two measurements. This limits the studies predictive value. In our study, neck and shoulder pain was assessed approximately every four months to minimize a possible recall bias. Furthermore, the work-related factors were treated as time independent, taking into account changes in these factors over time. The study population consisted of young adults in transition from studying to working life giving a population with no earlier exposure to work-related risk factors. Earlier studies investigating these relationships have mainly been conducted among middle-aged and older workers susceptible to a healthy worker effect, which may lead to an underestimation of the risk of neck and shoulder pain. The current study minimizes this effect by following all subjects regardless of change in occupational status.

The limitations of the present study include possible reporting bias as most of the data were collected through questionnaires. Self-reports may be influenced by, for example, personality dimensions such as negative affectivity (common method bias) (53). Follow- 
up studies often suffer from high drop-out rates, and self-administered questionnaires tend to be answered primarily by those who perceive the questions to be relevant (54). The high participation rate at baseline in the current study was possibly due to the fact that it was done during school hours, thereby including those who usually do not respond to questionnaires. Selection of individuals with musculoskeletal pain resulting in bias is, therefore, considered unlikely.

Studies of adolescents are often carried out on either high school or technical school students. Earlier studies comparing the two populations have found differences in health habits (24), limiting the external validity of our study to technical school students in their transition into working life.

Keeping the methodological limitations in mind, our study indicates that neck and shoulder pain increases over time in the transition from school to working life and both work-related and individual factors are associated with pain development. Even though the effects are relatively small, they may still be of importance when considering the population's young age and the short exposure time to work-related factors.

\section{Acknowledgments}

We want to thank Nina Østerås and Kristian Gould for their contribution to the data collection. This study was supported by a grant from the Confederation of Norwegian Enterprises (NHO).

The authors declare no conflicts of interest.

\section{References}

1. Vos T, Flaxman AD, Naghavi M, Lozano R, Michaud C, Ezzati M, et al. Years lived with disability (YLDs) for 1160 sequelae of 289 diseases and injuries 1990-2010: a systematic analysis for the Global Burden of Disease Study 2010. Lancet. 2012;380(9859):2163-96. http://dx.doi.org/10.1016/S01406736(12)61729-2.

2. Lærum EB, Brage S, Ihlebæk C, Johnsen K, Natvig B, Aas E. Et muskel- og skjelettregnskap. Forekomst og kostnader knyttet til skader, sykdommer og plager i muskel- og skjelettsystemet. [Musculoskeletal accounting. Incidence and costs of injuries, disorders and complaints of the musculoskeletal system.]. FORMI report nr.1. Oslo, Norway: Oslo University hospital; 2013.

3. Hakala P, Rimpelä A, Salminen JJ, Virtanen SM, Rimpelä M. Back, neck, and shoulder pain in Finnish adolescents: national cross sectional surveys. BMJ. 2002;325(7367):743. http:// dx.doi.org/10.1136/bmj.325.7367.743.
4. El-Metwally A, Salminen JJ, Auvinen A, Kautiainen H, Mikkelsson M. Prognosis of non-specific musculoskeletal pain in preadolescents: a prospective 4-year follow-up study till adolescence. Pain. 2004;110(3):550-9. http://dx.doi. org/10.1016/j.pain.2004.03.021.

5. Ståhl M, Kautiainen H, El-Metwally A, Häkkinen A, Ylinen J, Salminen JJ, Mikkelsson M. Non-specific neck pain in schoolchildren: prognosis and risk factors for occurrence and persistence. A 4-year follow-up study. Pain. 2008;137(2):316 22. http://dx.doi.org/10.1016/j.pain.2007.09.012.

6. Brattberg G. Do pain problems in young school children persist into early adulthood? A 13-year follow-up. Eur J Pain. 2004;8(3):187-99. http://dx.doi.org/10.1016/j. ejpain.2003.08.001.

7. Hoftun GB, Romundstad PR, Zwart JA, Rygg M. Chronic idiopathic pain in adolescence--high prevalence and disability: the young HUNT study 2008. Pain. 2011;152(10):2259-66. http://dx.doi.org/10.1016/j.pain.2011.05.007.

8. Harkness EF, Macfarlane GJ, Nahit ES, Silman AJ, McBeth J. Mechanical and psychosocial factors predict new onset shoulder pain: a prospective cohort study of newly employed workers. Occup Environ Med. 2003;60:850-7. http://dx.doi. org/10.1136/oem.60.11.850.

9. Hanvold TN, Veiersted KB, Wærsted M. A prospective study of neck, shoulder and upper back pain among technical school students entering working life. J Adolesc Health. 2010;46:48894. http://dx.doi.org/10.1016/j.jadohealth.2009.11.200.

10. Luime JJ, Koes BW, Miedem HS, Verhaar JAN, Burdorf A. High incidence and recurrence of shoulder and neck pain in nursing home employees was demonstrated during a 2-year follow-up. J Clin Epidemiol. 2005;58(4):407-13. http:// dx.doi.org/10.1016/j.jclinepi.2004.01.022.

11. Wahlström J, Hagberg M, Toomingas A, Wigaeus Tornqvist E. Perceived muscular tension, job strain, physical exposure, and associations with neck pain among VDU users; a prospective cohort study. Occup Environ Med. 2004;61(6):523-8. http:// dx.doi.org/10.1136/oem.2003.009563.

12. Christensen JO, Knardahl S. Work and neck pain: a prospective study of psychological, social, and mechanical risk factors. Pain. 2010;151(1):162-73. http://dx.doi.org/10.1016/j. pain.2010.07.001.

13. Cagnie B, Danneels L, Van Tiggelen D, De Loose V, Cambier D. Individual and work related risk factors for neck pain among office workers: a cross sectional study. Eur Spine J. 2007;16(5):679-86. http://dx.doi.org/10.1007/s00586-0060269-7.

14. Hamberg-van Reenen HH, Ariëns GAM, Blatter BM, Twisk JWR, van Mechelen W, Bongers PM. Physical capacity in relation to low back, neck, or shoulder pain in a working population. Occup Environ Med. 2006;63(6):371-7. http:// dx.doi.org/10.1136/oem.2006.026914.

15. Hamberg-van Reenen HH, Ariens GA, Blatter BM, van der Beek AJ, Twisk JW, van MW, et al. Is an imbalance between physical capacity and exposure to work-related physical factors associated with low-back, neck or shoulder pain? Scand J Work Environ Health. 2006;32(3):190-7. http://dx.doi. 
org/10.5271/sjweh.998.

16. Hannan LM, Monteilh CP, Gerr F, Kleinbaum DG, Marcus M. Job strain and risk of musculoskeletal symptoms among a prospective cohort of occupational computer users. Scand J Work Environ Health. 2005;31(5):375-86. http://dx.doi. org/10.5271/sjweh.921.

17. Ariëns GAM, van Mechelen W, Bongers PM, Bouter LM, van der Wal G. Psychosocial risk factors for neck pain: a systematic review. Am J Ind Med. 2001;39:180-93. http:// dx.doi.org/10.1002/1097-0274(200102)39:2<180::AIDAJIM1005>3.0.CO;2-\#.

18. Balogh I, Ørbæk P, Winkel J, Nordander C, Ohlsson K, EktorAndersen J, Group MS-NS. Questionnaire-based mechanical exposure indices for large population studies - reliability, internal consistency and predictive validity. Scand J Work Environ Health. 2001;27(1):41-8. http://dx.doi.org/10.5271/ sjweh.585.

19. Dallner M, Elo AL, Gamberale F, Hottinen V, Knardahl S, Lindström K, Skogstad A, et al. Validation of the General Nordic Questionnaire (QPSNordic) for psychological and social factors at work. Copenhagen: Nordic Council of Ministers, Nord; 2000.

20. Sterud T, Johannessen HA, Tynes T. Work-related psychosocial and mechanical risk factors for neck/shoulder pain: a 3-year follow-up study of the general working population in Norway. Int Arch Occup Environ Health. 2013; May 26. [Epub ahead of print]. http://dx.doi.org/10.1007/s00420-013-0886-5.

21. Reitan RM, Wolfson D. The Halstead-Reitan neuropsychological test battery. Theory and clinical implication. Arizona: Neuropsychology press; 1985.

22. Brox JI, Brevik JI, Ljunggren AE, Staff PH. Influence of anthropometric and psychological variables, pain and disability on isometric endurance of shoulder abduction in patients with rotator tendinosis of the shoulder. Scand J Rehab Med. 1996;28:193-200.

23. Nordander C, Ohlsson K, Balogh I, Rylander L, Pålsson B, Skerfving S. Fish processing work: the impact of two sex dependent exposure profiles on musculoskeletal health. Occup Environ Med. 1999;56:256-64. http://dx.doi.org/10.1136/ oem.56.4.256.

24. Wold B, Hetland J, Aarø LE, Samdal O, Torsheim T. Utviklingstrekk i helse og livsstil blant barn og unge fra Norge, Sverige, Ungarn og Wales. [Trends in health and lifestyle in children and adolescents in Norway, Sweden, Hungary and Wales. Results from nationwide surveys in "Health Behavior in School-aged Children, a WHO Cross-National Study (HBSC)"]. HEMIL report no.1. Bergen: Research Centre for Health Promotion, University of Bergen, Norway; 2000.

25. Wærsted M, Hæg LB, Hanvold TN, Hansson GÅ, Veiersted KB. Vocational muscle activity and perceived muscle tension in young adults. Adv in Physiother. 2012;14:107-14. http://dx.doi.org/10.3109/14038196.2012.700730.

26. Kuorinka I, Jonsson B, Kilbom Å, Vinterberg H, BieringSørensen F, Andersson G, Jørgensen K. Standardised Nordic questionnaires for the analysis of musculoskeletal symptoms. Appl Ergon. 1987;18(3):233-7. http://dx.doi. org/10.1016/0003-6870(87)90010-X.
27. Steingrímsdóttir ÓA, Vøllestad NK, Røe C, Knardahl S. Variation in reporting of pain and other subjective health complaints in a working population and limitations of single sample measurements. Pain. 2004;110(1-2):130-9. http:// dx.doi.org/10.1016/j.pain.2004.03.016.

28. Steingrímsdóttir ÓA: Subjective health complaints and their relation to muscle responses in a working population [dissertation]. Oslo, Norway: Faculty of Medicine, University of Oslo and National Institute of Occupational Health; 2005.

29. Spratt M, Carpenter J, Sterne JAC, Carlin JB, Heron J, Henderson J, Tilling K. Strategies for multiple imputation in longitudinal studies. Am J Epidemiol. 2010;172(4):478-87. http://dx.doi.org/10.1093/aje/kwq137.

30. Rubin DB: Multiple imputation after $18+$ years. J Am Stat Assoc. 1996;91(434):473-89. http://dx.doi.org/10.1080/016 21459.1996.10476908.

31. Mehlum IS, Kjuus H, Veiersted KB, Wergeland E. Selfreported work-related health problems from the Oslo Health Study. Occup Med. 2006;56(6):371-9. http://dx.doi. org/10.1093/occmed/kq1034.

32. Siivola SM, Levoska S, Latvala K, Hoskio E, Vanharanta H, Keinänen-Kiukaanniemi S. Predictive factors for neck and shoulder pain: a longitudinal study in young adults. Spine. 2004;29(15):1662-9. http://dx.doi.org/10.1097/01. BRS.0000133644.29390.43.

33. Niemi S, Levoska S, Kemilä J, Rekola K, KeinänenKiukaanniemi S. Neck and shoulder symptoms and leisure time activities in high school students. J Orthop Sports Phys Ther. 1996;24(1):25-9. http://dx.doi.org/10.2519/ jospt.1996.24.1.25.

34. Vikat A, Rimpela M, Salminen JJ, Rimpela A, Savolainen A, Virtanen SM. Neck or shoulder pain and low back pain in Finnish adolescents. Scand J Public Health. 2000;28(3):164 73. http://dx.doi.org/10.1080/140349400444850.

35. Mehlum IS, Kristensen P, Veiersted KB, Wærsted M, Punnett L. Does the threshold for reporting musculoskeletal pain or the probability of attributing work-relatedness vary by socioeconomic position or sex? J Occup Environ Med. 2013;55(8):901-9. http://dx.doi.org/10.1097/ JOM.0b013e31828dc8ec.

36. Punnett L, Herbert R: Work-related musculoskeletal disorders: is there a gender differential, and if so, what does it mean? In: Goldman MB, Hatch MC. editors. Women Health. San Diego: Academic Press; 2000: p. 474-92. http://dx.doi.org/10.1016/ B978-012288145-9/50044-9.

37. Hooftman WE. Gender differences in work-related risk factors for musculoskeletal symptoms aand absenteeism. [dissertation]. Amsterdam, The Netherlands:body@work and the EMGO Institute of the VU University Medical Center; 2006.

38. Nordander C, Ohlsson K, Balogh I, Hansson GÅ, Axmon A, Persson R, et al. Gender differences in workers with identical repetitive industrial tasks: exposure and musculoskeletal disorders. Int Arch Occup Environ Health. 2008;81(8):939-47. http://dx.doi.org/10.1007/s00420-007-0286-9. 
39. Bradshaw L, Harris-Roberts J, Bowen J, Rahman S, Fishwick D. Self-reported work-related symptoms in hairdressers. Occup Med. 2011;61(5):328-34. http://dx.doi.org/10.1093/ occmed/kqr089.

40. Bernard BP. editor. Musculoskeletal disorders and workplace factors. A critical review of epidemiologic evidence for workrelated musculoskeletal disorders of the neck, upper extremity, and low back. Cincinnati, OH: U.S. Department of health and Human Services, NIOSH; 1997.

41. Sporrong H, Sandsjö L, Kadefors R, Herberts P. Assessment of workload and arm position during different work sequences: a study with portable devices on construction workers. Appl Ergon. 1999;30(6):495-503. http://dx.doi.org/10.1016/ S0003-6870(99)00016-2.

42. da Costa BR, Vieira ER. Risk factors for work-related musculoskeletal disorders: A systematic review of recent longitudinal studies. Am J Ind Med. 2010;53(3):285-323.

43. Karasek RA. Job demands, job decision latitude, and mental strain; implications for job redesign. Adm Sci Quarterly. 1979;24:285-308. http://dx.doi.org/10.2307/2392498.

44. Vasseljen O, Johansen BM, Westgaard RH. The effect of pain reduction on perceived tension and EMG-recorded trapezius muscle activity in workers with shoulder and neck pain. Scand J Rehabil Med. 1995;27(4):243-52.

45. Huysmans MA, Blatter BM, van der Beek AJ. Perceived muscular tension predicts future neck-shoulder and arm-wristhand symptoms. Occup Environ Med. 2012;69(4):261-7. http://dx.doi.org/10.1136/oemed-2011-100279.

46. Holte KA, Vasseljen O, Westgaard RH. Exploring perceived tension as a response to psychosocial work stress. Scand J Work Environ Health. 2003;29(2):124-33. http://dx.doi. org/10.5271/sjweh.714.

47. Alexopoulos EC, Burdorf A, Kalokerinou A. A comparative analysis on musculoskeletal disorders between Greek and Dutch nursing personnel. Int Arch Occup Environ Health. 2006;79(1):82-8. http://dx.doi.org/10.1007/s00420-0050033-z.
48. Wang PC, Rempel DM, Harrison RJ, Chan J, Ritz BR. Workorganisational and personal factors associated with upper body musculoskeletal disorders among sewing machine operators. Occup Environ Med. 2007;64(12):806-13. http://dx.doi. org/10.1136/oem.2006.029140.

49. Komiyama O, Kawara M, De Laat A. Ethnic differences regarding tactile and pain thresholds in the trigeminal region. J Pain. 2007;8(4):363-9. http://dx.doi.org/10.1016/j. jpain.2006.12.002.

50. Barnekow-Bergkvist M, Hedberg G, Janlert U, Jansson E. Development of muscular endurance and strength from adolescence to adulthood and level of physical capacity in men and women at the age of 34 years. Scand J Med Sci Sports. 1996;6(3):145-55. http://dx.doi. org/10.1111/j.1600-0838.1996.tb00082.x.

51. Barnekow-Bergkvist M, Hedberg GE, Janlert U, Jansson E. Determinants of self-reported neck-shoulder and low back symptoms in a general population. Spine. 1998;23(2):235-43. http://dx.doi.org/10.1097/00007632-199801150-00017.

52. Hamberg-van Reenen HH, Ariens GA, Blatter BM, van MW, Bongers PM. A systematic review of the relation between physical capacity and future low back and neck/shoulder pain. Pain. 2007;130(1-2):93-107. http://dx.doi.org/10.1016/j. pain.2006.11.004.

53. Podsakoff PM, MacKenzie SB, Lee JY, Podsakoff NP. Common method biases in behavioral research: a critical review of the literature and recommended remedies. J Appl Psychol. 2003;88(5):879-903. http://dx.doi.org/10.1037/00219010.88.5.879.

54. Dickinson CE, Campion K, Foster AF, Newman SJ, O'Rourke AMT, Thomas PG. Questionnaire development: an examination of the Nordic Musculoskeletal questionnaire. Appl Ergon. 1992;23(3):197-201. http://dx.doi.org/10.1016/00036870(92)90225-K.-

Received for publication: 17 February 2014 